\title{
SPECIES RICHNESS IN A SUCCESSIONAL GRASSLAND: EFFECTS OF NITROGEN ENRICHMENT AND PLANT LITTER
}

\author{
Bryan L. Foster ${ }^{1}$ AND Katherine L. Gross \\ W. K. Kellogg Biological Station and Michigan State University, Hickory Corners, Michigan 49060 USA
}

\begin{abstract}
We conducted a field experiment in a successional grassland to investigate the short-term effects of nitrogen enrichment and plant litter on plant species richness and on the establishment of a native grass (Andropogon gerardi) that was experimentally introduced to the study site as seed. Additions of nitrogen fertilizer to experimental plots over two growing seasons increased plant production as indicated by increases in both living plant biomass and litter biomass. Increased productivity reduced species richness by effectively preventing the seedling establishment of the subordinate forb species and reduced the recruitment of Andropogon gerardi by inhibiting both germination and survival. Litter removals carried out at each of two levels of nitrogen enrichment (no nitrogen, nitrogen added) showed that litter significantly reduced species richness by the same amount in fertilized and unfertilized plots, suggesting that living biomass and litter were purely additive, rather than interactive in their effects. In contrast, the results of litter additions suggested that the declines in richness associated with fertilization could largely be due to the suppressive effects of increased litter biomass alone. As a whole, the results indicate that litter and living biomass are largely substitutable in their inhibitory effects on species richness in highly productive successional grasslands due to their independent and equivalent capacities to attenuate light to very low levels. This study highlights the combined roles of competition and plant litter in influencing the diversity of grasslands through effects on seedling establishment.
\end{abstract}

Key words: Andropogon gerardi; competition; diversity; establishment; litter addition and removal; litter biomass; living biomass; nitrogen enrichment; productivity; species richness; successional grassland.

\section{INTRODUCTION}

The addition of limiting nutrients to herbaceous plant communities frequently leads to increases in plant production and declines in plant species diversity (e.g., Bakelaar and Odum 1978, Tilman 1987, Carson and Barrett 1988, Pysek and Leps 1991, Tilman 1993). There is considerable interest in the mechanisms responsible for reduced diversity at high levels of fertility and productivity, not only for theoretical reasons, but also because of practical concerns regarding the consequences that long-term eutrophication may have for the conservation and restoration of native plant communities (Berendse and Elberse 1990, Marrs et al. 1996). A number of prominent theories have focused on resource competition and its potential role in determining the effects of productivity on species diversity in plant communities (Grime 1973, 1979, Newman 1973, Goldberg and Miller 1990, Tilman and Pacala 1993, Huston and DeAngelis 1994). Most of these theories suggest that competition for light occurring among living plants at high productivity results in

Manuscript received 17 March 1997; revised 11 June 1997; accepted 31 December 1997.

${ }^{1}$ Present address: Department of Ecology, Evolution and Behavior, University of Minnesota, St. Paul, Minnesota 55108 USA. E-mail: foster@swan.lter.umn.edu greater competitive exclusion and reduced species richness (Abrams 1995). Although resource competition among living plants is undoubtedly important in limiting the diversity of many plant communities, these theories generally do not consider the potential role of accumulated plant litter in contributing to reduced diversity at high levels of plant productivity. A number of studies suggest that a dense litter layer can limit the diversity of productive habitats by inhibiting species establishment through a variety of mechanisms, including through the effects of shading and mechanical impediment (Goldberg and Werner 1983, Carson and Peterson 1990, Tilman 1993, Facelli 1994).

Plant litter can play an important role in structuring plant communities by directly and indirectly affecting individuals and populations (Sydes and Grime 1981, Carson and Peterson 1990, Facelli and Pickett 1991). There are studies illustrating both positive and negative effects of plant litter on the performance of plants. Positive species interactions have gained renewed attention by ecologists (Bertness and Callaway 1994), and plant litter may be an important factor mediating these interactions in extremely unproductive or arid environments where even small amounts of litter can ameliorate stressful environmental conditions (e.g., low moisture levels; Fowler 1986, Willms et al. 1986, Hamrick and Lee 1987). Inhibition by litter is most 
commonly observed in highly productive but undisturbed environments, where litter accumulation can be quite high (Goldberg and Werner 1983, Carson and Peterson 1990, Tilman 1993, Foster and Gross 1997). Together, these studies suggest that litter may influence species diversity along fertility and productivity gradients via changes in the sign (facilitation vs. inhibition) and magnitude of its effects.

In this study we investigated the effects of nitrogen enrichment and plant litter on species richness in a successional grassland in southwest Michigan. Prior to European settlement, the herbaceous component of the upland prairie and savanna communities of southwest Michigan were largely occupied by native grasses and a diverse array of prairie forbs. It is generally recognized that these species and communities were maintained by frequent fire (Gotshall 1972). In tallgrass prairies, fire serves to remove plant litter, thus altering species composition, productivity, and diversity (Hulbert 1969, Knapp and Seastedt 1986). Grass litter accumulation has been frequently cited as an important factor contributing to reduced yield and reduced diversity when fires are suppressed over long time periods in tallgrass prairie (Hulbert 1969, Knapp and Seastedt 1986).

In the current successional landscape of southwest Michigan, upland herbaceous old fields are typically dominated by introduced grasses such as Bromus inermis and Agropyron repens, which are capable of invading and dominating old fields shortly after abandonment from agriculture (Tilman and Wedin 1991, Foster 1992). Because fire is currently absent from this landscape, the rapid accumulation of grass litter may be an unique feature of these successional grasslands that limits species establishment and diversity, especially in the most productive fields that have become eutrophied by past agricultural activity (fertilization, manure application, or other causes) and have accumulated very large amounts of litter. Litter accumulation may be particularly important in inhibiting the reestablishment of displaced native grassland species that evolved in the presence of fire, and which may lack adaptations for establishment in dense litter (Tilman 1993).

The primary goals of our study were to examine the short-term effects of nitrogen enrichment on plant community biomass, species abundance, and species richness within a moderately productive successional grassland in southwest Michigan, and to examine the extent to which these effects could be attributed to changes in litter biomass, independently of changes in standing crop or living plant biomass. To critically examine the role of litter in contributing to changes in community structure that are associated with nutrient enrichment and increased productivity, it is necessary to manipulate litter levels in concert with fertilization. In this study, we report the results of a two-year field experiment in which the experimental addition of ni- trogen fertilizer was accompanied by the experimental removal and addition of plant litter.

Another objective of this study was to examine the impact of nitrogen enrichment and litter accumulation on the reestablishment potential of a single native grassland species. This was done by adding seed of Andropogon gerardi, a native perennial bunchgrass, to the experimental plots. Andropogon was absent from the site at the time of the study, both as established plants and as seed, thus allowing assessment of seedling recruitment from a known seed pool. Although this once-dominant prairie species is common in the current landscape, it is primarily restricted to low and medium fertility sites and is largely absent from the most fertile old fields. Establishment of native perennial grasses from seed is generally rare in intact prairie vegetation. However, establishment from seed represents the only mechanism through which Andropogon can reinvade areas from which it had been previously displaced by agriculture. In this study, seed additions allowed us to assess whether the absence of Andropogon from the study site, and from the more productive old fields in the region, may be due more to its inability to establish from seed or simply due to limits on dispersal.

\section{Methods \\ Study site}

This study was conducted in southwest Michigan at the W. K. Kellogg Biological Station (KBS) of Michigan State University (Kalamazoo County; 42 $24^{\prime} \mathrm{N}$, $\left.85^{\circ} 24^{\prime} \mathrm{W}\right)$. The experimental site was located within a midsuccessional old field (20-30 yr postagricultural abandonment) that was dominated by introduced perennial grasses: Bromus inermis, Agropyron repens, and Phleum pratense. These species accounted for $>80 \%$ of the total community biomass. The litter layer in this field was composed almost entirely of grass stem and leaf material, mainly from the dominant grass species, Bromus inermis. The most common forb species in the community were Daucus carota, Achillea millefolium, Hypericum perforatum, and Potentilla recta. Soils underlying the field site are a well-drained, Oshtemo sandy loam formed from glacial till and are of moderate fertility for the region (Foster and Gross 1997).

\section{Experimental design and procedure}

In mid-April 1994, we established six $2.5 \times 2.5 \mathrm{~m}$ experimental blocks at the study site. The blocks were arranged in two parallel columns of three blocks each that were separated by a 2-m buffer strip. Blocks within each column were separated by buffer zones of $1 \mathrm{~m}$. Within each block, four $1 \times 1 \mathrm{~m}$ treatment plots were established and placed so that there was a $0.5-\mathrm{m}$ buffer between each plot (one plot at each corner of the block). Experimental treatments representing two levels of ni- 
trogen (no nitrogen, nitrogen added) and two levels of litter (litter removed, litter left intact) were randomly assigned to the four treatment plots within each block. We later added a litter addition treatment (LA) to examine the effects of increased litter biomass, independently of nitrogen enrichment. The objective of the litter addition treatment was to add a quantity of litter similar to the additional amount expected to accumulate naturally in response to nitrogen enrichment. To accommodate this extra treatment, one additional $1 \times$ $1 \mathrm{~m}$ plot for the LA treatment was added to each block in June 1994. These plots were systematically positioned $0.5 \mathrm{~m}$ away from one side of each of the original blocks. As a result, there was not a complete randomization of all treatments within the blocks.

Litter was removed from the appropriate plots in April and November 1994 by clipping around the perimeter of the plots and then gently lifting the litter mat by hand. This assured that there was no disturbance to the soil surface. Litter was removed in November to remove the current year's production that had died and fallen into the plots as litter. In March 1995 a small amount of litter blown into these plots over the winter was removed by hand.

Nitrogen was applied to the nitrogen enrichment plots as commercial ammonium nitrate fertilizer at a rate of $48 \mathrm{~g} \mathrm{~N} \cdot \mathrm{m}^{-2} \cdot \mathrm{yr}^{-1}$. The pelletized fertilizer was applied twice annually ( $24 \mathrm{~g} \mathrm{~N}$ per application), in late April and mid-June of 1994 and 1995. This rate is $\sim 50 \%$ higher than that typically applied to agricultural fields in the region. We chose a relatively high rate of nitrogen enrichment for this experiment to ensure a large biomass response, and to mimic the high productivity of the most fertile upland grasslands in the region.

During the first growing season (1994), the litter addition plots were left untreated until late November, when grass litter was added to each of the plots. Litter was added in November because a significant increase in litter biomass in response to nitrogen enrichment (i.e., within plots where nitrogen was added and litter left intact, NA treatment) did not occur until the end of the first growing season. Litter collected nearby was weighed, and then spread evenly across the litter addition plots. The amount of litter added (374 g) was determined by collecting litter from a $0.1 \times 1 \mathrm{~m}$ strip in the control plots (i.e., within plots where no nitrogen was added and litter left intact, $C$ treatment) and the NA treatment plots. The litter was weighed and the average difference in litter biomass between these two treatments was determined (374 g). After weighing, this litter was returned to the $\mathrm{C}$ and NA plots. To assure that the litter added to the LA treatment plots was not blown away during the winter months, we loosely stretched two strands of baling wire across each plot and anchored the ends of the wire in the soil.

\section{Andropogon seed addition}

To examine the effects of nitrogen enrichment and litter on the recruitment of Andropogon gerardi, locally collected seeds of Andropogon were added to each 1 $\times 1 \mathrm{~m}$ experimental plot in May 1995. Within each plot, 300 seeds were added to a single, permanently marked $30 \times 30 \mathrm{~cm}$ quadrat that was located within one quadrant of the plot. The three remaining quadrants within each plot were reserved for community-level sampling harvests. Seeds were evenly broadcast by hand into the quadrats from $\sim 30 \mathrm{~cm}$ above the soil. Germination and survivorship of Andropogon seedlings were monitored throughout the growing season. On each of six census dates, newly germinated seedlings were marked with color-coded toothpicks, and plants marked in previous censuses were accounted for as dead or alive. Data are reported as percent germination (fraction of added seed that germinated by the time of harvest) and percent survival (fraction of the resulting seedlings that survived to harvest).

\section{Light measurements}

To determine the effect of the experimental manipulations on the quantity of light reaching the soil surface, we measured photosynthetically active radiation (PAR) in each of the plots in early August 1995. PAR measurements were taken $\sim 50 \mathrm{~cm}$ above the vegetation and at the soil surface in each plot using a PAR ceptometer probe (Decagon Devices Incorporated). In plots where litter was left intact, measurements were made by inserting the ceptometer probe beneath the litter layer. Light penetration was expressed as the percentage of the PAR above the vegetation that reached the soil surface.

\section{Vegetation sampling and data analysis}

In late August 1995, aboveground living plant biomass and litter were harvested from each plot within three $30 \times 30 \mathrm{~cm}$ community sampling quadrats. Each of these quadrats was centered within one of the three remaining plot quadrants. In addition, all aboveground biomass of Andropogon was harvested from the permanently marked, $30 \times 30 \mathrm{~cm}$ seed addition quadrat that was located in the fourth quadrant of each plot. Living biomass from the community sampling quadrats was sorted to species and individual forbs were counted. All plant material was dried at $60^{\circ} \mathrm{C}$ to constant mass and weighed.

For each $1 \times 1 \mathrm{~m}$ plot, plant biomass and forb densities were summed across the three community sampling quadrats and then expressed at the plot level on a per square meter basis. Andropogon densities determined from the seed addition quadrats were also expressed on a per square meter basis. Because species richness does not generally scale with area, we present species richness for each plot as the sum of species found across all three community sampling quadrats. 
Treatment effects on plant abundances, species richness, and Andropogon germination and survival were examined using two separate analyses. First, we omitted the litter addition treatment (LA) and analyzed data from the remaining four treatments using a randomized block $2 \times 2$ factorial ANOVA. This allowed us to test for the main effects of nitrogen and litter and to evaluate their potential interaction. In cases where a significant nitrogen $\times$ litter interaction was found, we used unplanned contrasts to compare means within each factor level (Sokal and Rohlf 1981). A second analysis was used to assess the impact of litter addition (LA) on each dependent variable. In most cases the LA treatment was compared with the control treatment (C) using paired $t$ tests. In some cases comparisons were made between the LA, the NA, and the control treatment $(\mathrm{C})$ using one-way ANOVA followed by Tukey's pairwise comparisons. Much of the data were highly heteroscedastic and so were transformed to meet the assumptions of ANOVA. Biomass data were log-transformed, density and richness data were square-root transformed, and Andropogon germination and survival data were arcsine transformed prior to analysis. Untransformed means are presented in the figures and tables. Statistical analyses were performed using SYSTAT: Statistics, Version 5.2 edition (Wilkinson et al. 1992).

\section{RESUlTS}

\section{Community responses}

Plant biomass.-Nitrogen enrichment increased plant community productivity as reflected by significant increases in both living biomass (Fig. 1A) and litter (Fig. 1B) in response to fertilization. In contrast, litter had no significant effect on living biomass (Fig. 1A). Similarly, a separate analysis comparing biomass responses in the litter addition (LA) and control (C) treatments showed that litter addition had no impact on living biomass. As intended for the establishment of proper treatment conditions, the removal of litter drastically reduced litter biomass (Fig. 1B). Also as intended, the addition of litter (LA treatment) led to a significant increase in litter biomass (relative to the $\mathrm{C}$ treatment) up to a level that was not significantly different from that which had accumulated naturally in response to nitrogen (NA treatment).

The increase in plant biomass observed in response to nitrogen enrichment reflects a strong positive effect of fertilization on grasses (Fig. 1C), primarily through effects on the dominant species, Bromus inermis (Table 1). However, none of the litter manipulations had any effect on total grass biomass (Fig. 1C) or the biomass of Bromus (Table 1). Forb biomass, which was much lower than grasses overall, was not significantly affected by nitrogen, litter, or by litter addition (Fig. 1D).

Light penetration. - The manipulation of living and litter biomass in this experiment greatly affected light penetration to the soil surface (Fig. 2). Light levels varied significantly with nitrogen, litter, and with the interaction between the two. Treatment comparisons made within each factor level indicate that nitrogen reduced light penetration significantly in both the absence and presence of litter, but that litter reduced light penetration significantly only in treatments where no nitrogen was added. The addition of litter strongly reduced light penetration (relative to the $\mathrm{C}$ treatment) to the same low level found in the NA treatment.

Species richness. - Both nitrogen and litter led to significant declines in species richness (Fig. 1E). Litter reduced richness by the same amount in both the unfertilized and fertilized treatments (no nitrogen $\times$ litter interaction). Litter addition reduced richness to a level not significantly different from that found in the NA treatment.

Forb density. - The pronounced negative effects of nitrogen enrichment and plant litter on species richness appears to be related to the suppressive impacts of these factors on the establishment of forb seedlings. Unlike forb biomass, forb density was significantly reduced by both nitrogen and litter (Fig. 1F). As was observed for species richness, the degree to which litter reduced forb density did not appear to be influenced by nitrogen (no nitrogen $\times$ litter interaction). Litter addition reduced forb density to a level not significantly different from that found in the NA treatment.

The densities of biennial and perennial forbs were reduced significantly by nitrogen and litter (Table 2). Perennial forb density was also significantly reduced by litter addition. Although not evaluated statistically, annual forb density appeared to be negatively affected by litter. Annual seedlings were found in all replicates of the two litter removal treatments. However, no annual forbs were found in the fertilized treatment that contained litter (NA treatment) or the LA treatment.

Treatment effects on biennial forb densities reflect the responses of the most abundant forb species, Daucus carota. The density of Daucus was reduced significantly by both nitrogen and litter, but was not significantly affected by litter addition. For the second most abundant forb species, Achillea millefolium, there were no significant main effects on density, but there was a significant interaction between nitrogen and litter. Comparisons made within each factor level indicate that nitrogen enrichment had a strong negative impact on Achillea density only in the treatments where litter was present. Also, litter reduced Achillea density only in the fertilized plots. The addition of litter significantly reduced Achillea density relative to the control treatment.

\section{Andropogon recruitment}

Germination and survivorship.-We examined Andropogon germination and survival in response to the experimental treatments to assess the relative importance of each process in determining Andropogon recruitment (final density). Andropogon germination var- 
Litter removed

A Litter intact

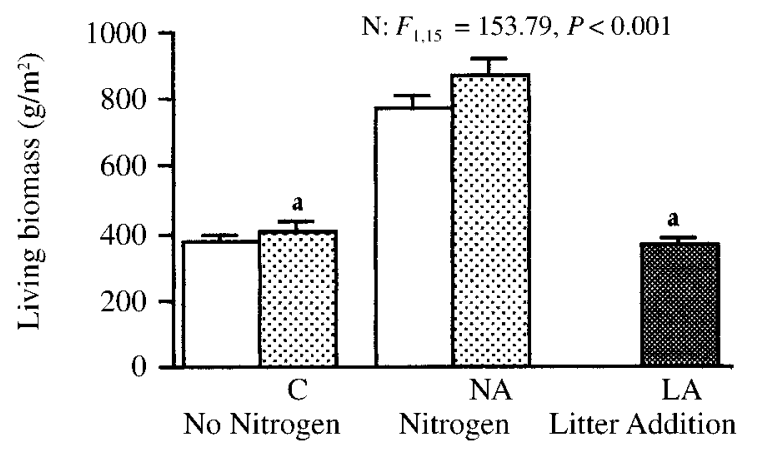

$\mathrm{C}$

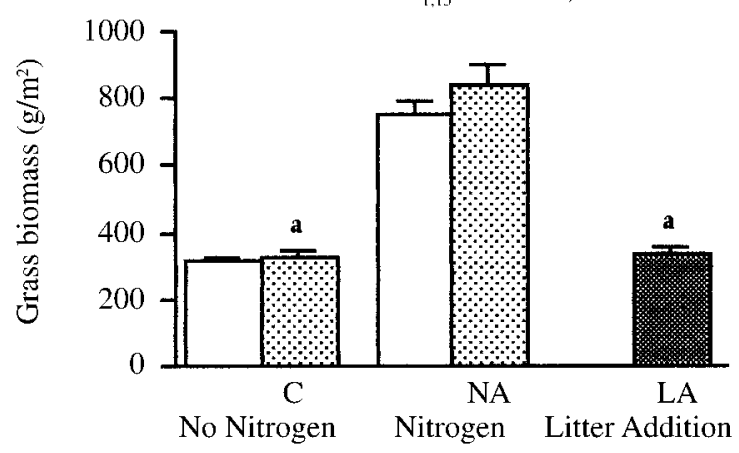

$\mathrm{E}$

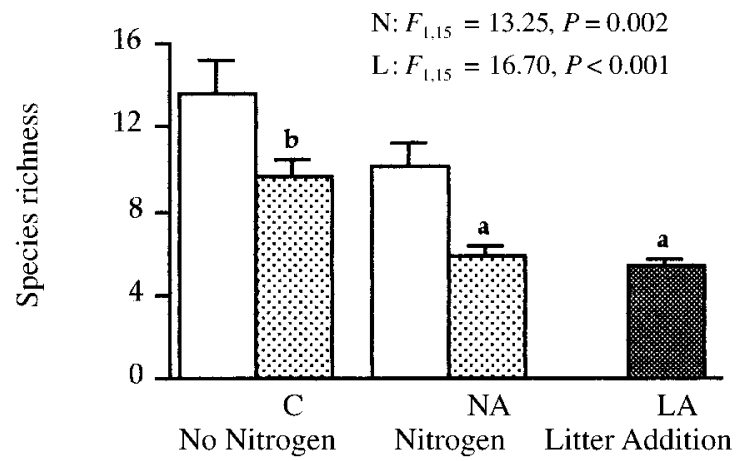

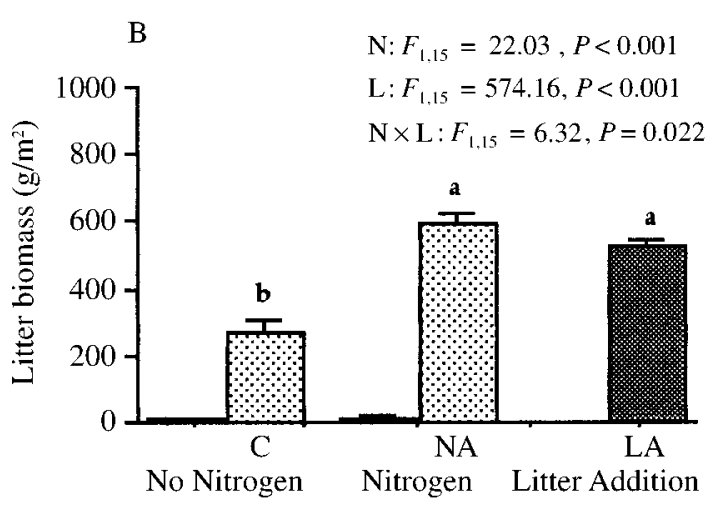

D

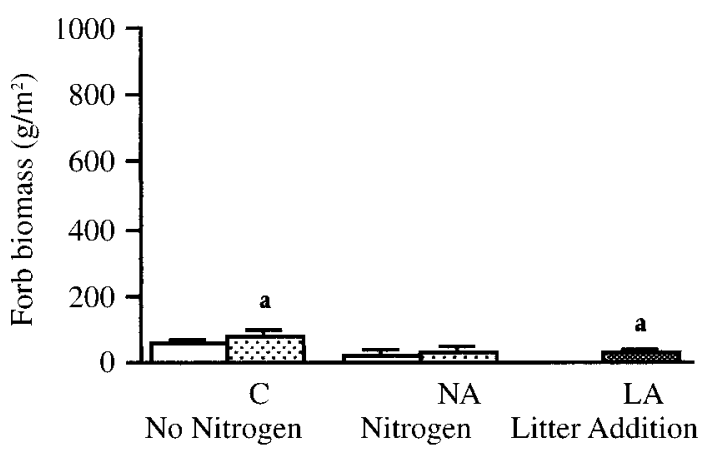

F

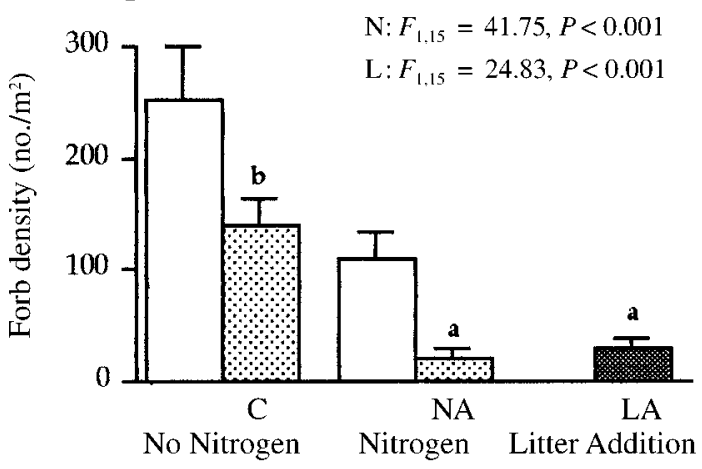

FIG. 1. Treatment effects on (A) living biomass, (B) litter biomass, (C) grass biomass, (D) forb biomass, (E) species richness, and (F) forb density. Bars represent means +1 SE. Significant terms of the $2 \times 2$ factorial ANOVA (which excludes the litter addition treatment $)$ are presented. $(\mathrm{B}=$ block, $\mathrm{N}=$ nitrogen, $\mathrm{L}=$ Litter, and $\mathrm{N} \times \mathrm{L}=$ nitrogen $\times$ litter interaction.) Lowercase letters are placed above the bars of treatments that were compared in separate analyses using either paired $t$ tests $(\mathrm{df}=11)$ or one-way ANOVA $(\mathrm{df}=2,10)$. Treatments with the same letters are not significantly different $(P>0.05)$. C $=$ control treatment (litter intact, no nitrogen added); NA = nitrogen addition treatment (litter intact, nitrogen added); LA $=$ litter addition treatment.

ied significantly in response to nitrogen, litter, and with the interaction between the two (Fig. 3A). In general, nitrogen and litter strongly suppressed germination. Comparisons within each level of nitrogen indicated that litter reduced germination significantly in both the unfertilized and fertilized treatments. However, a marginally significant nitrogen $\times$ litter interaction reflects that the magnitude of the effect of litter was somewhat greater in the unfertilized treatments. Litter addition strongly suppressed germination to a level not significantly different from the NA treatment. Nitrogen enrichment strongly reduced seedling survival, but there was no significant effect of litter or a nitrogen $\times$ litter interaction (Fig. 3B). Seedling survival was highly variable in the litter addition treatment and did not differ significantly from the NA treatment.

Final density and biomass per plant.-Nitrogen enrichment strongly reduced the final density and biomass 
TABLE 1. Comparisons of mean biomass of grass species among the experimental treatments.

\begin{tabular}{|c|c|c|c|c|c|c|c|c|c|}
\hline \multirow[b]{3}{*}{ Species } & \multirow{2}{*}{\multicolumn{4}{|c|}{ Treatment effects }} & \multicolumn{5}{|c|}{ Biomass $\left(\mathrm{g} / \mathrm{m}^{2}\right)$} \\
\hline & & & & & \multicolumn{2}{|c|}{-Nitrogen } & \multicolumn{2}{|c|}{ + Nitrogen } & \multirow[b]{2}{*}{ LA } \\
\hline & $\begin{array}{l}\text { Significant } \\
\text { effects }\end{array}$ & $F$ & $\mathrm{df}$ & $P$ & -Litter & + Litter & - Litter & +Litter & \\
\hline Bromus inermis & $\mathrm{N}$ & 123.48 & 1,15 & $<0.001$ & 215.2 & 200.3 & 571.7 & 703.3 & $272.4^{\mathrm{NS}}$ \\
\hline Agropyron repens & B & 3.93 & 5,15 & 0.018 & 43.6 & 64.4 & 95.4 & 69.2 & $32.6^{\mathrm{NS}}$ \\
\hline Phleum pratense & (none) & $\ldots$ & $\ldots$ & $\ldots$ & 28.7 & 40.3 & 43.9 & 53.4 & $22.9^{\mathrm{NS}}$ \\
\hline Poa pratensis & (none) & $\ldots$ & $\ldots$ & $\ldots$ & 18.3 & 16.7 & 33.5 & 13.2 & $9.2^{\mathrm{NS}}$ \\
\hline Panicum sp. & (none) & $\cdots$ & $\ldots$ & $\cdots$ & 5.2 & 3.1 & 7.9 & 2.6 & $2.2^{\mathrm{NS}}$ \\
\hline Poa compressa & $\mathrm{NT} \dagger$ & $\ldots$ & $\ldots$ & $\ldots$ & 1.2 & 2.3 & 0.2 & 0.7 & \\
\hline
\end{tabular}

Notes: Factorial ANOVAs $(2 \times 2)$ were performed for each species that had adequate variation in biomass in each of the four relevant treatments. Only the significant terms in these ANOVAs $(\mathrm{B}=$ block, $\mathrm{N}=$ nitrogen, $\mathrm{L}=1$ itter, $\mathrm{N} \times \mathrm{L}=$ nitrogen $\times$ litter interaction) are shown. Superscripts next to values in the litter addition (LA) column specify the nonsignificance (NS; $P>0.05)$ of paired $t$ tests $(\mathrm{df}=11)$ in separate analyses that compared the litter addition and control $(\mathrm{C})$ treatments.

$\dagger \mathrm{NT}=$ not tested due to inadequate variation in biomass in one or more treatments.

per plant of Andropogon to very low levels (Fig. 3C and D). Litter also strongly reduced density and biomass per plant, but only in the absence of nitrogen enrichment (significant nitrogen $\times$ litter interaction). Litter addition reduced Andropogon density and biomass per plant to a level not significantly different from that found in the NA treatment.

\section{Discussion}

In this successional grassland, nitrogen fertilizer applied over two growing seasons led to increased plant production, increased litter accumulation, and reduced species richness as reported in numerous other nutrient enrichment experiments (Tilman 1987, Carson and Barrett 1988, Wilson and Shay 1990, Pysek and Leps 1991). Our results also indicate that the negative effect of nitrogen enrichment on species richness largely occurred through the inhibition of forb seedling establishment. This experiment was also designed to partition out the effects of nitrogen enrichment caused by accumulated plant litter from effects caused by increases in living plant biomass. We found that plant litter

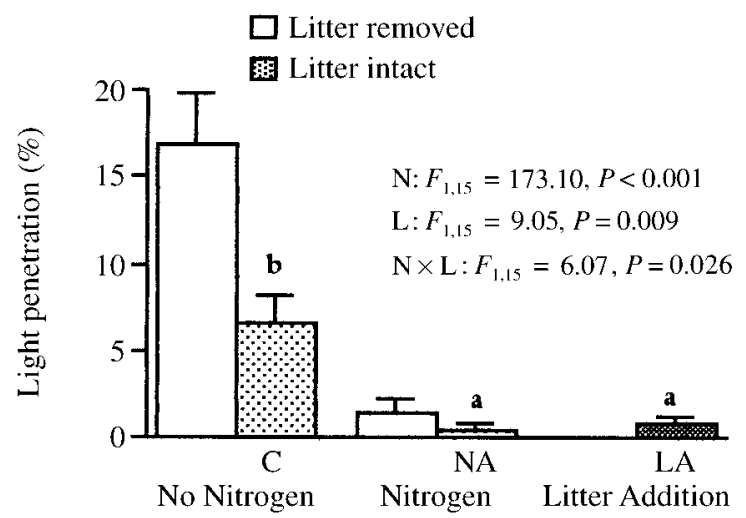

FIG. 2. Treatment effects on light penetration (means + $1 \mathrm{SE})$. See Fig. 1 legend for details on the ANOVA and significance levels. strongly reduced species richness by inhibiting the establishment of forb seedlings.

However, the results of the factorial ANOVA indicate that the significant negative effects of nitrogen and litter on forb establishment and species richness were purely additive (no nitrogen $\times$ litter interaction). This suggests that reductions in forb establishment and species richness observed in response to nitrogen enrichment in treatments where litter was left intact (NA vs. $\mathrm{C}$ treatment) did not occur through the effects of increased litter, despite the fact that nitrogen enrichment effectively doubled litter biomass. In isolation, this result suggests that there may be a litter biomass threshold that limits species richness to a certain level in this field (the level found in the control treatment), and that further increases in litter biomass above this threshold may have no additional impact. Under this interpretation the low species richness found in the NA treatment might reflect the effect of this litter threshold plus the added impact of nitrogen enrichment that occurred through the effects of increased living biomass.

However, litter addition strongly reduced forb establishment and species richness relative to the control treatment and to the same low level found in the NA treatment. In contrast to the results of the factorial ANOVA, this suggests that the increase in litter biomass by itself could explain the observed reduction in forb establishment and species richness that occurred in response to nitrogen enrichment (NA vs. C).

How do we reconcile these seemingly contradictory results? One possibility is that the negative impact of litter caused by the litter addition treatment was an artifact of our methods. Perhaps placement of the litter in the LA treatment was such that the litter layer was more compact and impenetrable to seeds and seedlings than the litter layer in the NA treatment. We view this as unlikely because of the great care taken in the placement of the litter. If anything, the litter layer in the LA treatment plots was less compact and would likely have resulted in reduced mechanical resistance to seedling 
TABLE 2. Comparisons of mean forb density among the experimental treatments. Means are presented for life history groups and for the 10 most common forb species. Analyses are presented as described in Table 1 .

\begin{tabular}{|c|c|c|c|c|c|c|c|c|c|}
\hline \multirow[b]{3}{*}{ Species } & \multirow{2}{*}{\multicolumn{4}{|c|}{ Treatment effects }} & \multicolumn{5}{|c|}{ Density (no./m²) } \\
\hline & & & & & \multicolumn{2}{|c|}{-Nitrogen } & \multicolumn{2}{|c|}{ + Nitrogen } & \multirow[b]{2}{*}{ LA } \\
\hline & $\begin{array}{c}\text { Significant } \\
\text { effects }\end{array}$ & $F$ & $\mathrm{df}$ & $P$ & - Litter & $\begin{array}{c}+ \text { Litter } \\
\text { (C) }\end{array}$ & - Litter & + Litter & \\
\hline Annual forbs & $\mathrm{NT} \dagger$ & $\ldots$ & $\ldots$ & $\ldots$ & 49.9 & 3.4 & 19.1 & & \\
\hline Biennial forbs & $\begin{array}{l}\mathrm{N} \\
\mathrm{L}\end{array}$ & $\begin{array}{r}14.86 \\
9.87\end{array}$ & $\begin{array}{l}1,15 \\
1,15\end{array}$ & $\begin{array}{l}0.002 \\
0.007\end{array}$ & 88.7 & 53.9 & 43.8 & 9.5 & $16.3^{\mathrm{NS}}$ \\
\hline Perennial forbs & $\begin{array}{l}\mathrm{N} \\
\mathrm{L}\end{array}$ & $\begin{array}{r}23.03 \\
7.66\end{array}$ & $\begin{array}{l}1,15 \\
1,15\end{array}$ & $\begin{array}{r}<0.001 \\
0.014\end{array}$ & 114.0 & 84.8 & 46.6 & 13.0 & $14.1 * *$ \\
\hline Daucus carota & $\begin{array}{l}\mathrm{N} \\
\mathrm{L}\end{array}$ & $\begin{array}{r}9.17 \\
10.65\end{array}$ & $\begin{array}{l}1,15 \\
1,15\end{array}$ & $\begin{array}{l}0.008 \\
0.005\end{array}$ & 85.9 & 44.9 & 41.6 & 8.9 & $16.3^{\mathrm{NS}}$ \\
\hline Achillea millefolium & $\mathrm{N} \times \mathrm{L}$ & 6.19 & 1,15 & 0.025 & 22.5 & 24.7 & 25.8 & 6.2 & $10.7 *$ \\
\hline Hypericum perforatum & NT & $\cdots$ & $\cdots$ & $\cdots$ & 25.3 & 42.7 & 6.2 & 0.6 & \\
\hline Potentilla recta & NT & $\ldots$ & $\cdots$ & $\cdots$ & 14.6 & 10.1 & 8.4 & & 0.6 \\
\hline Oxalis stricta & NT & $\cdots$ & $\ldots$ & $\ldots$ & 16.3 & & 8.9 & & \\
\hline Trifolium repens & NT & $\ldots$ & $\ldots$ & $\cdots$ & 25.3 & & & & \\
\hline Rumex acetosella & NT & $\ldots$ & $\ldots$ & $\ldots$ & 10.7 & 3.4 & 5.6 & & \\
\hline Medicago lupulina & NT & $\ldots$ & $\ldots$ & $\ldots$ & 11.2 & 3.4 & 2.3 & & \\
\hline Mullugo verticillata & NT & $\ldots$ & $\ldots$ & $\ldots$ & 10.1 & & & & \\
\hline Chenopodium album & NT & $\ldots$ & $\ldots$ & $\ldots$ & 2.8 & & 5.6 & & \\
\hline
\end{tabular}

Note: Superscripts next to values in the litter addition (LA) column specify the significance of paired $t$ tests $(\mathrm{df}=11)$ in separate analyses that compared the litter addition and control (C) treatments: $* P<0.05, * * P<0.01$, ${ }^{\text {NS }} P>0.05$.

$\dagger \mathrm{NT}=$ not tested due to inadequate variation in biomass in one or more treatments.

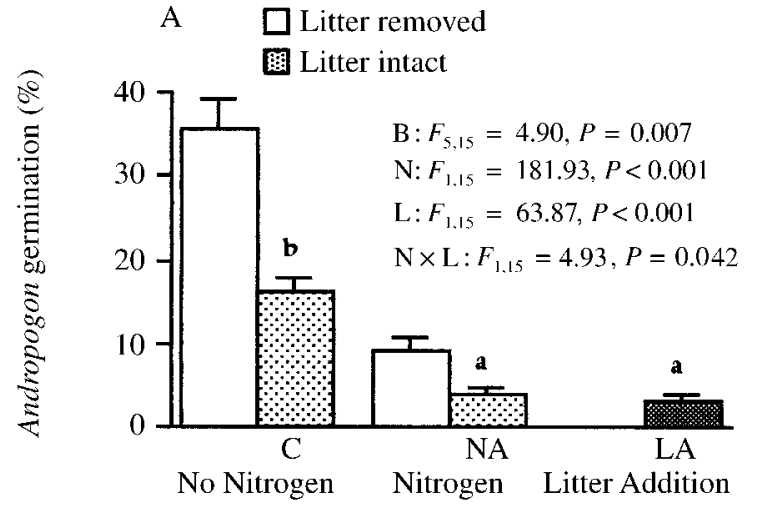

$\mathrm{C}$

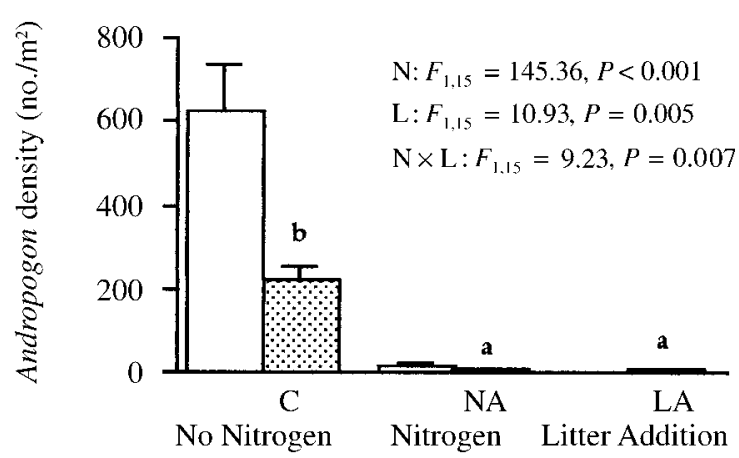

B

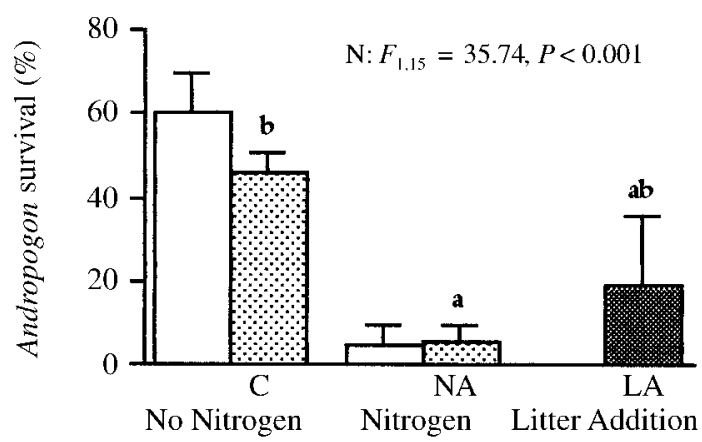

D

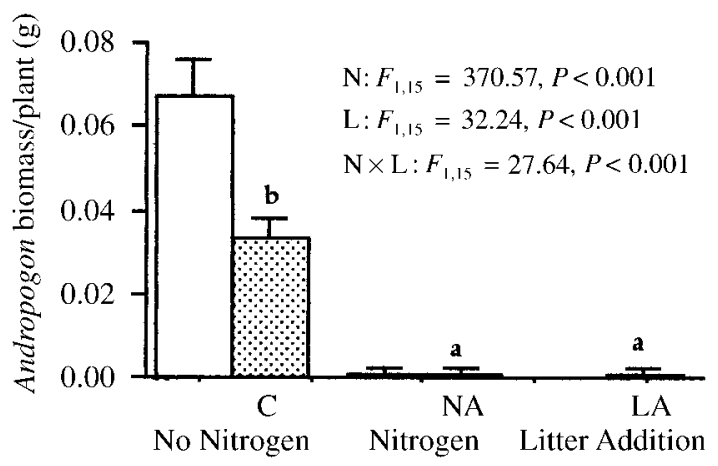

FIG. 3. Treatment effects on (A) Andropogon germination, (B) survival, (C) final plant density, and (D) biomass per plant (means $+1 \mathrm{SE}$ ). See Fig. 1 legend for details on the ANOVA and significance levels. 
establishment relative to the NA treatment. Also, seeds imbedded in the added litter were not removed before placement. Therefore, it is likely that the LA plots had more seeds in them at the start of the experiment than in the NA plots. Both of these factors would have biased toward showing a weaker impact of litter on seedling establishment and richness than expected in the NA treatment where similar amounts of litter accumulated naturally.

It is very likely that both the addition of nitrogen to the NA plots and the addition of litter to the LA plots reduced species richness to the lowest possible level in this experiment by effectively eliminating forb seedling establishment, thus primarily leaving in place only those forb species represented by larger established individuals. Therefore, the lack of significant interaction between nitrogen and litter found in the factorial ANOVA does not necessarily mean that the large amount of additional litter biomass that accumulated in response to nitrogen enrichment was incapable of suppressing richness further, but rather that the lower limit to species richness had been reached in the NA treatment, effectively preventing the expression of these additional litter effects. It appears likely then that the additional living biomass and litter that accumulated in the NA treatment (relative to the control) in response to nitrogen enrichment were both capable of independently and equally preventing the recruitment of forbs. So although the factorial ANOVA suggested that living biomass and litter are additive in their effects, the litter addition results suggest that living biomass and litter may be substitutable in their effects at high levels of productivity, likely due to their independent and equivalent capacities to reduce light penetration to levels that are inhospitable to seedling establishment.

Most theories designed to explain the interdependence of species diversity and productivity invoke the mechanism of competition for light occurring among living plants in causing species extinctions and reductions in diversity at high levels of productivity (Goldberg and Miller 1990, Tilman and Pacala 1993, Huston and DeAngelis 1994, Abrams 1995). Shading was undoubtedly an important factor influencing diversity in this study. However, our results suggest that shading by litter, in addition to shading by living plant biomass, was very important in limiting diversity. Litter reduced light levels in the fertilized and unfertilized plots and in the litter addition plots in ways that were consistent with the effects of litter on forb establishment and richness. Both living biomass and litter had very similar effects on light penetration, indicating that shading by plant biomass in general, regardless of whether it is dead or alive, is an important factor influencing the diversity of this grassland. Although we suggest that the negative effects of litter observed in this study occurred primarily through shading, we suspect other direct and indirect mechanisms could be involved. For example, litter may negatively affect plants by acting as a mechanical barrier or by promoting the increased activity of pathogens (Facelli and Pickett 1991).

Several studies indicate that the effects of fertility and productivity on diversity in old-field and grassland communities may be strongly influenced by the inhibitory effects of accumulated plant litter in addition to competition (Carson and Peterson 1990, Tilman 1993, Foster and Gross 1997, Gough and Grace 1998). As in our study, Carson and Peterson (1990) found that experimental additions of plant litter reduced plant density and species richness in a Solidago-dominated old field. From this they argued that low diversity in highly productive old fields and reductions in diversity often observed in nutrient enrichment experiments may be caused by a combination of both inhibition by litter and resource competition associated with living plants. Tilman (1993) found that declines in species richness associated with long-term nitrogen enrichment in experimental grasslands was more strongly related to variation in litter biomass than to variation in living biomass. These results were largely attributed to the negative impacts of litter on the establishment of seedlings and the establishment of new species in the most productive plots.

\section{Andropogon recruitment}

The purpose of adding Andropogon seeds to the experimental plots was to examine the effects of nitrogen enrichment and litter on the establishment potential of a single species. The results give insight into the effects of dispersal limitation and inhibition on the establishment success of this native species in southwest Michigan old fields that differ in soil fertility, plant productivity, and accumulated plant litter. Unlike what was observed for forbs in the factorial analysis, nitrogen and litter were highly interactive in their effects on Andropogon recruitment. Nitrogen drastically reduced final Andropogon density and biomass per plant to near zero in plots both with and without litter. As a result there was no effect of litter in the fertilized treatments, probably because establishment was prevented by shading associated with increased living biomass. However, litter did reduce Andropogon density and biomass in the unfertilized plots, indicating that litter represents a significant constraint to recruitment in this field. Despite inhibition by litter, Andropogon was able to establish a large number of seedlings in the control plots, suggesting that the absence of this species from this study site, and other sites of moderate productivity, may be largely due to limits on propagule availability rather than to inhibition of seedling recruitment by the established vegetation. The equally strong negative impacts of litter addition and nitrogen enrichment on Andropogon recruitment suggests that the reduced density and biomass of Andropogon observed in the NA treatment (relative to the control) can be suitably explained by the independent effects of either litter or living biomass. So as was seen for forbs, it appears that living 
biomass and litter were substitutable in their effects on Andropogon recruitment, likely due to their equivalency in attenuating light. Living biomass and litter appear to have differed somewhat in their mechanisms of inhibition, in that litter reduced Andropogon recruitment only through its effect on germination, while living biomass appeared to suppress both germination and seedling survival. These results suggest that the absence of Andropogon from highly productive fields in the region that support a high standing crop may be due to inhibition of seedling establishment by the established vegetation in addition to any limits on propagule availability. These results, and those from a previous study that examined recruitment from seed across a range of sites that varied naturally in productivity (Foster 1996, Foster and Gross 1997), indicate that establishment limitation in the most productive habitats may be very important in restricting the distribution of native grasses such as Andropogon along old-field productivity gradients in southwest Michigan.

\section{Establishment limitation}

An assumption implicit in most competition-based diversity theories is that increased productivity reduces species richness because it causes an increase in the rate of species loss (Tilman 1993). However, the number of species within a habitat at a given time can be determined by a balance between colonization and extinction processes (MacArthur and Wilson 1969). Tilman (1993) found that species establishment and extinction were equally important in determining the species richness of grasslands, and argued that earlier theories should be modified to account for the effects of productivity on establishment. The results of our study are consistent with the conclusion that increased productivity can reduce species richness in grassland by reducing the probability of establishment. Although we did not directly track the gains and losses of individual plants or species over time in this study, it was clear that the decline in species richness associated with nitrogen enrichment was primarily due to the inhibition of forb seedling establishment. Also, the strong negative impact of nitrogen enrichment on the germination, survival, and density of Andropogon observed in this study highlights the role of increased productivity in limiting the establishment potential of a single species.

To our knowledge this is the first study utilizing litter manipulations in conjunction with fertilization to explicitly examine the separate effects of plant litter and living plants in contributing to changes in community structure associated with nutrient enrichment and increased productivity. The results are in concordance with the frequently observed decline in species richness in response to nutrient enrichment and increased plant productivity, but suggest that the mechanisms responsible for these declines may potentially involve the inhibitory effects of litter on establishment, in addition to the competitive effects of living plants. In agreement with Tilman (1993), we suggest that theories designed to explain the observed interdependence of species richness and productivity in herbaceous vegetation should take into account the potential role of accumulated plant litter in limiting establishment and species richness in productive habitats.

\section{ACKNOWLEDGMENTS}

We thank J. Leversee for assistance in the field. We greatly appreciate the comments and suggestions made by H. Reynolds, L. Gough, and T. Miller on earlier drafts of the manuscript. Support was provided by the KBS graduate Research Training Group (RTG) funded by NSF grant DIR-09113598, NSF LTER grant BSR 8702332, and a George H. Lauff Research Award. This is contribution number 867 of the W. K. Kellogg Biological Station.

\section{Literature Cited}

Abrams, P. A. 1995. Monotonic or unimodal diversity-productivity gradients: what does competition theory predict? Ecology 76:2019-2027.

Bakelaar, R. G., and E. P. Odum. 1978. Community and population level responses to fertilization in an old-field ecosystem. Ecology 59:660-665.

Berendse, F., and W. T. Elberse. 1990. Competition and nutrient availability in heathland and grassland ecosystems. Pages 93-116 in J. B. Grace and D. Tilman, editors. Perspectives on plant competition. Academic Press, San Diego, California, USA.

Bertness, M. D., and R. Callaway. 1994. Positive interactions in communities: a post cold war perspective. Trends in Ecology and Evolution 9:191-193.

Carson, W. P., and G. W. Barrett. 1988. Succession in oldfield plant communities: effects of contrasting types of nutrient enrichment. Ecology 69:984-994.

Carson, W. P., and C. J. Peterson. 1990. The role of litter in an old-field community: impact of litter quantity in different seasons on plant species richness and abundance. Oecologia 85:8-13.

Facelli, J. M. 1994. Multiple indirect effects of plant litter affect the establishment of woody seedlings in old fields. Ecology 75:1727-1735.

Facelli, J. M., and S. T. A. Pickett. 1991. Plant litter: its dynamics and effects on plant community structure. Botanical Review 57:1-31.

Foster, B. L. 1992. The role of land use history in structuring an old field plant community. Thesis. Michigan State University, East Lansing, Michigan, USA.

- 1996. Plant competition and diversity in relation to productivity in old-field plant communities. Dissertation. Michigan State University, East Lansing, Michigan, USA.

Foster, B. L., and K. L. Gross. 1997. Partitioning the effects of plant biomass and litter on Andropogon gerardi in oldfield vegetation. Ecology 78:2091-2104.

Fowler, N. L. 1986. Microsite requirements for germination and establishment of three grass species. American Midland Naturalist 115: 131-145.

Goldberg, D. E., and T. E. Miller. 1990. Effects of different resource additions on species diversity in an annual plant community. Ecology 71:213-225.

Goldberg, D. E., and P. A. Werner. 1983. The effects of size of opening in vegetation and litter cover on seedling establishment of goldenrods (Solidago spp.). Oecologia 60: 149-155.

Gotshall, T. B. 1972. The vegetation of Kalamazoo County at the time of settlement. Pages 1-21 in R. Brewer, editor. The ecology of Kalamazoo County. Western Michigan University Press, Kalamazoo, Michigan, USA.

Gough, L., and J. B. Grace. 1998. Herbivore effects on plant 
species density at varying productivity levels. Ecology $\mathbf{7 9}$ : $1586-1594$.

Grime, J. P. 1973. Competitive exclusion in herbaceous vegetation. Nature 242:344-347.

. 1979. Plant strategies and vegetation processes. J. Wiley and Sons, Chichester, UK.

Hamrick, J. L., and J. M. Lee. 1987. Effect of soil surface topography and litter cover on the germination, survival, and growth of musk thistle (Carduus nutans). American Journal of Botany 74:451-457.

Hulbert, L. C. 1969. Fire and litter effects in undisturbed bluestem prairie in Kansas. Ecology 50:874-877.

Huston, M. A., and D. L. DeAngelis. 1994. Competition and coexistence: the effects of resource transport and supply rates. American Naturalist 144:954-977.

Knapp, A. K., and T. R. Seastedt. 1986. Detritus accumulation limits productivity of tallgrass prairie. BioScience 36:662-668.

MacArthur, R. H., and E. O. Wilson. 1967. The theory of island biogeography. Princeton University Press, Princeton, New Jersey, USA.

Marrs, R. H., J. B. Grace, and L. Gough. 1996. On the relationship between plant species diversity and biomass a comment on a paper by Gough, Grace and Taylor. Oikos 75:323-326.

Newman, E. I. 1973. Competition and diversity in herbaceous vegetation. Nature 244:310.

Pysek, P., and J. Leps. 1991. Response of a weed community to nitrogen fertilization: a multivariate analysis. Journal of Vegetation Science 2:237-244.

Sokal, R. R., and F. J. Rohlf. 1981. Biometry. W. H. Freeman, New York, New York, USA.

Sydes, C., and J. P. Grime. 1981. Effects of tree leaf litter on herbaceous vegetation in deciduous woodlands. Journal of Ecology 69:237-248.

Tilman, D. 1987. Secondary succession and the pattern of plant dominance along experimental nitrogen gradients. Ecological Monographs 57:189-214.

. 1993. Species richness of experimental productivity gradients: how important is colonization limitation? Ecology 74:2179-2191.

Tilman, D., and S. Pacala. 1993. The maintenance of species richness in plant communities. Pages 13-25 in R. E. Ricklefs and D. Schluter, editors. Species diversity in ecological communities: historical and geographical perspectives. University of Chicago Press, Chicago, Illinois, USA.

Tilman, D., and D. Wedin. 1991. Plant traits and resource reduction for five grasses growing on a nitrogen gradient. Ecology 72:685-700.

Wilkinson, L., M. A. Hill, and E. Vang. 1992. SYSTAT: Statistics, Version 5.2 edition. SYSTAT, Evanston, Illinois, USA.

Willms W. D., S. Smoliak, and A. W. Baily. 1986. Herbage production following litter removal on Alberta native grasslands. Journal of Range Management 39:536-540.

Wilson S. D., and J. M. Shay. 1990. Competition, fire, and nutrients in a mixed-grass prairie. Ecology 71:1959-1967. 